\title{
Global Competitiveness and Economic Growth: Empirical Verification for African Countries
}

\author{
Mohamed BEN AMAR ${ }^{1} \&$ Mohamed Tlili HAMDI ${ }^{2}$ \\ ${ }^{1}$ Faculty of Economics and Management of Sfax, Tunisia \\ ${ }^{2}$ Higher Institute of Administration and Business of Sfax, Tunisia \\ Correspondence: Mohamed Tlili HAMDI, Institut Supérieure d'Administration des Affaires de Sfax, Route de \\ l'Aéroport Km 4, BP no1013, Sfax 3018, Tunisia. Tel: 216-21-292-993. E-mail: benamarmoha@gmail.com
}

Received: March 29, 2012

doi:10.5539/ijef.v4n6p125

\author{
Accepted: May 6, 2012 \\ Published: June 1, 2012 \\ URL: http://dx.doi.org/10.5539/ijef.v4n6p125
}

\begin{abstract}
The target of this work consists of analyzing economic growth in African countries. We have three main results that were generated from this work. First, the pillars of global competitiveness are strongly inspired by the theories of endogenous growth. Secondly, concerning economic growth, African countries realized some impressive performances during the last decade and show very important potential. Finally, by means of panel data evaluation for a sample of 23 African countries during the period (2004-2009), we confirmed the positive and statistically significant effect of economic growth, driven by the level of the global competitiveness.
\end{abstract}

Keywords: global competitiveness, pillars for competitiveness, panel data, endogenous growth, African countries

JEL Classification: $\mathrm{C} 23, \mathrm{O} 40$, $\mathrm{O} 55$

\section{Introduction}

A few years ago, the international institutions (particularly the World Bank and the International Monetary Fund) and international economic and financial consultant (Goldman Sachs, McKinsey \& Company and other) mentioned African countries in their reports. In other words, the economic evolution of the African countries is interested by the whole world.

"The potential of Africa is vast. While the African economies as a group are unlikely to challenge the BRICs (Note) (...), they could deliver significant growth and higher incomes over the next several decades" (Note 2)

In this way, these organizations spoke of the economic growth dimension realized in the African continent. They also spoke of the existing potential of the continent concerning natural resources and other factors of economic growth. Moreover, these organizations analyzed in detail exogenous and endogenous factors, that brought about such performances. Indeed, they estimate that the improvement of the competitiveness of the African countries during the last decade played a big role in the realization of such results.

The aim of our work consists of evaluating empirically the effect of global competitiveness on the economic growth of a group of African countries. To treat such an issue, we will organize our work in three sections. The object of the first section is to search for the link between the pillars of the global competitiveness, used by the World Economic Forum, and the main models of endogenous growth, that represent the modern theory of economic growth. The second section presents the impressive performances of the African countries in terms of realization of their existing capacities. The last section is devoted to our empiric verification of effects of global competitiveness level on economic growth in the case of a sample of African countries.

\section{The Assessment of the Global Competitiveness: A Strong Inspiration of the Endogenous Growth Models}

The World Economic Forum, in its different reports of assessment of global competitiveness, used twelve pillars for competitiveness divided into three groups. The first group is related to the basic parameters: institutions, infrastructures, macroeconomic stability, health and primary education. The second group represents the sources of efficiency: efficiency of health and primary education, efficiency of the markets and products, efficiency of the labor markets, sophistication of the financial markets, opening to technology and size of the market. The third group concerns the sources of efficiency: sophistication of the enterprises and innovation.

In reality, the majority of these different pillars of competitiveness represent, explicitly or implicitly, the factors of endogenous growth. Thus, Romer (1986) supposed that physical capital is a source of endogenous growth. 
Therefore, as the accumulation of the physical capital and the production increase, there is a stock of knowledge that is going to be accumulated and that is going to exercise positive externalities on the activities of the other firms. Implicitly, several institutions can encourage the accumulation of this factor by some means (Note 3) Lucas (1988) also developed an endogenous growth model centered on the human capital, which accumulated by the means of some activities of which the most significant were education, training, health and the innovation. In the same way, Romer (1990) and Aghion and Howitt (1992) developed two models of endogenous growth where the source of growth is in technological innovation (Note 4). Barro (1990) also proposed a model that clarifies the role of infrastructures in the generation of economic growth by the effects of practice that they exercise on the productivity of the private factors (Note 5). In 1993, Pagano also analyzed theoretically the role of financial development in the efficient allocation of financial resources and therefore in economic growth. Finally, Grossman and Helpman (1991) proposed a model where economic growth depends on the opening-up of the economy. This opening encourages technological transfers and opens new foreign markets.

Generally, the majority of the pillars of global competitiveness used by the World Economic Forum in its different assessments are inspired by endogenous growth models developed since the middle of the eighties of the last century (table 1).

Table 1. The inspiration for the pillars of global competitiveness from the models of endogenous growth

\begin{tabular}{|c|c|c|c|}
\hline Pillar of competitiveness & Pillar 1 & Pillar 2 & Pillar 3 \\
\hline $\begin{array}{l}\text { Endogenous growth } \\
\text { model inspiration }\end{array}$ & $\begin{array}{l}\text { Romer (1986): institutions } \\
\text { Barro } \\
\text { infrastructures } \\
\text { Lucas (1988): health and } \\
\text { primary education }\end{array}$ & $\begin{array}{l}\text { Lucas (1988): health and primary } \\
\text { education } \\
\text { Pagano (1993): sophistication of financial } \\
\text { markets } \\
\text { Grossman et Helpman (1991): opening to } \\
\text { the technology and size of the market }\end{array}$ & $\begin{array}{l}\text { Romer (1990) et Aghion et Howitt } \\
\text { (1992): sophistication of firms and } \\
\text { innovation }\end{array}$ \\
\hline
\end{tabular}

Source: conception of authors

In this table, we insist only on the explicit inspiration. Other implicit inspirations can be evoked. For instance, institutions have implicitly an important role in the accumulation of human capital, technological innovation, financial development and the opening-up of the economy.

\section{Economic Growth in African Countries: The Principal Results of the Report of McKinsey Global Institute (Note 6)}

In this section, we are going to describe the findings about economic growth in African countries. We will be interested as well by the achieved performances and of the existing potential. Our reference will be the report "Lions on the Move: the Progress and Potential of Africa Economies" published in 2010 by McKinsey Global Institute.

Concerning economic performances, the African countries achieved a great improvement during the last decade. Thus, the African GDP registered 4.9\% like on average yearly growth during the period 2000-2008. This rate has more doubled from the one of the years 1980 and 1990. African GDP reached in 20081.600 billion dollars; nearly the equivalent of that of Brazil and Russia. Nevertheless, the expenditures of consumption in 2008 are estimated at 860 billion dollars. Finally, after a constant decrease during the eighties and nineties, labor productivity in Africa returned to increase with a strong average yearly growth of $3 \%$ during the period 2000-2008. The boom in raw materials prices contributed directly to the rate of $24 \%$ in the economic growth of the African countries during the period 2000-2008. This rate can reach 32\% if we also consider the indirect contributions.

Actually, in addition to the increase in raw materials prices, there were other factors that played a great role in the realization of these performances. These factors improved African countries global competitiveness.

"The key reasons behind Africa's growth surge include government moves to end armed conflicts, improve macroeconomic conditions, and adopt microeconomic reforms to create a better business climate. In every country where these shifts occurred, they correlated with faster GDP growth" (Note 7).

For most African countries, political stability is improved by the reduction of the levels of conflict. Several macroeconomic and microeconomic reforms were adopted: privatization of the public corporations, reduction of trade barriers, tax relief on the profit of companies and reinforcement of the legal systems and regulation. Concerning macroeconomic stability, between 1990 and 2000, the rate of inflation declined from $22 \%$ to $8 \%$ (Note 
8), the proportion of public debt in the GDP fell from $81.9 \%$ to $59 \%$ (Note 9) and the part of the budget deficit in the GDP also declined from $-4.6 \%$ to $-1,8 \%$ (Note 10 ).

This macroeconomic and political stability, combined with these economic reforms have improved the level of African countries competitiveness by the creation of the economics of scale in several sectors, especially the commercial sector.

In addition to the performances already achieved concerning economic growth, Africa possesses a great potential for future economic growth.

"If recent trends continue, Africa will play an increasing important role in the global economy. By 2040, the continent will be home to one in five of the planet's young people, and the size of its labor force will top China's. Companies already operating in Africa should consider expanding (Note 11)".

Thus, African GDP in 2020 is estimated at 2.6 trillion dollar. In the same way, the spending of consumption in Africa is also estimated at 1.4 trillion dollars in 2020. These estimates are based on a number of factors. First, concerning resources, Africa has important world reserves: $10 \%$ in oil, $40 \%$ in gold, $80 \%$ in chrome and $90 \%$ in the platinum metals. Secondly, concerning social and demographic changes, the rate of urbanization is estimated to reach $50 \%$ in 2030. Finally, Africa is the youngest continent on the planet and the number of workers in Africa is estimated to reach 1.1 billion in 2040 .

In reality, the net amelioration of the African countries concerning global competitiveness explains these achieved performances and the potential estimates of the African countries concerning economic growth. To explain the relationship between these aggregates, we use a longitudinal estimate (graphic below).

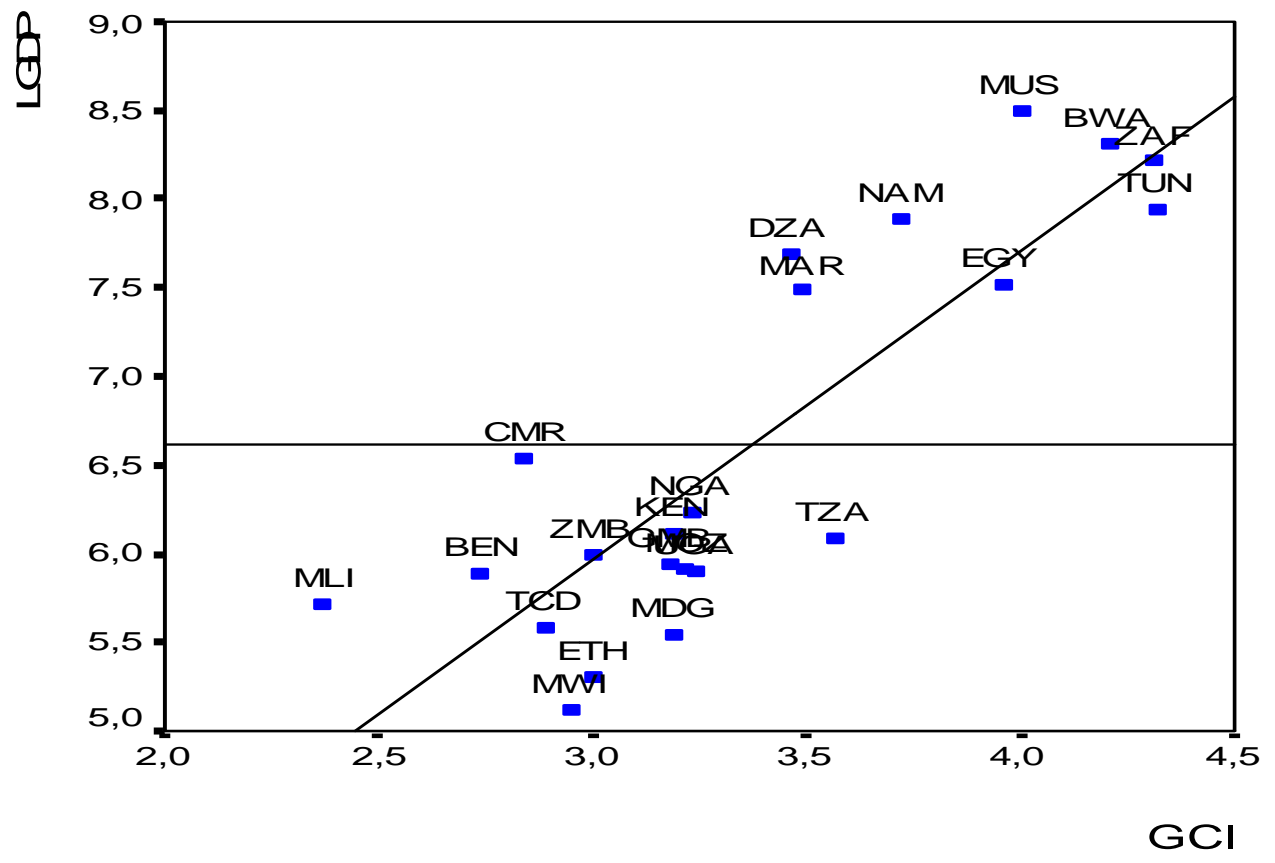

Figure1. The relationship between GDP per capita and GCI

This diagram highlights the positive relation that exists between the two studied variables; the GDP per capita (LGDP) and the Global Competitiveness Index (GCI). In the year of our study (2009) (Note 12), it appears that the obtained results present the interest to analyze a large sample of countries with different levels of development (in the African continent). The countries in the top and on the right of the diagram are the more developed and they have high-levels of competitiveness. On the other hand, the countries in the bottom and on the left represent the less developed and they have the weakest GCI. These results attest to a positive relationship between global competitiveness and economic development level that is going to be the subject of empiric verification in the following section. 


\section{Global Competitiveness and Economic Growth: An Empirical Verification for A Sample of African Countries}

In this section, we are going to study empirically the effects of global competitiveness on economic growth for a sample of African countries (Note 13). To attain such a target, we will follow the approach of Mankiw, Romer \& Weil (1992) and Demetriades \& Law (2004).

We retain the Cobb-Douglas production function:

$$
Y_{t}=K_{t}^{\alpha} H_{t}^{\beta}\left(A_{t} L_{t}\right)^{1-\alpha-\beta}
$$

with, $L_{t}=L_{o} e^{n_{t}} \quad$ et $\quad A_{t}=A_{0} e^{g_{t}+\rho_{t} \theta}$

where, $\mathrm{Y}$ is the real output, $\mathrm{K}$ is the stock of physical capital, $\mathrm{H}$ is the stock of human capital, $\mathrm{L}$ is the labor, $\mathrm{A}$ is the factor reflecting the level of technology and the efficiency in the economy, $\mathrm{n}$ is the rate of the labor force growth, $\mathrm{g}$ is the rate of technological progress supposed constant, $\rho$ is the vector representing the global competitiveness and other factors that can affect the level of technology and efficiency in the economy, $\theta$ is the vector of coefficients related to these variables, the subscript $t$ indicates time. It is assumed that $\alpha+\beta<1$.

The evolution of the economy is represented by:

$$
\dot{K}_{t}=\frac{d K_{t}}{d_{t}}=s_{k} Y_{t}-\delta K_{t} \quad \& \quad \dot{H}_{t}=\frac{d H_{t}}{d_{t}}=s_{h} Y_{t}-\delta H_{t}
$$

Where, $s_{k}$ and $s_{h}$ are respectively the rate of investment in physical capital and the rate of investment in human capital.

We suppose that: $\dot{K}_{t}=I_{t}-\delta K_{t}$ and $I_{t}=S_{t}$

Where, $\delta$ is the rate of the physical capital depreciation.

We consider that the production by unit of labor, the physical capital stock by unit of labor and the human capital stock by unit of labor are given by:

$$
y_{t}=\frac{Y_{t}}{A L_{t}} ; \quad k_{t}=\frac{K_{t}}{A L_{t}} \quad \text { and } \quad h_{t}=\frac{H_{t}}{A L_{t}}
$$

After all developments, we obtain:

$$
\begin{gathered}
\dot{k_{t}}=s_{k} y_{t}-(n+g+\delta) k_{t} \\
\dot{h_{t}}=s_{h} y_{t}-(n+g+\delta)
\end{gathered}
$$

We consider that the gross domestic product per effective worker is written as follows:

$$
y_{t}=\frac{Y_{t}}{A L_{t}}=k_{t}^{\alpha} h_{t}^{\beta}
$$

The substitution of (5) in (3) and in (4), produces:

$$
\begin{aligned}
& \dot{k_{t}}=s_{k} k_{t}^{\alpha} h_{t}^{\beta}-(n+g+\delta) k_{t} \\
& \dot{h_{t}}=s_{h} k_{t}^{\alpha} h_{t}^{\beta}-(n+g+\delta) h_{t}
\end{aligned}
$$

At the equilibrium, we have: $\dot{k_{t}}=\dot{h_{t}}=0$

This result conducts us to the following relations:

$$
\begin{gathered}
s_{k} k_{t}^{\alpha} h_{t}^{\beta}=(n+g+\delta) k_{t} \\
s_{h} k_{t}^{\alpha} h_{t}^{\beta}=(n+g+\delta) h_{t}
\end{gathered}
$$

On dividing (8) by (9), we obtain:

$$
h=\frac{s_{h}}{s_{h}} k
$$

The substitution of (10) in (9) and (8), shows us to the following relation:

$$
\begin{aligned}
& k^{*}=\left(\frac{s_{k}^{1-\beta} s_{h}^{\beta}}{n+g+\delta}\right)^{\frac{1}{1-\alpha-\beta}} \\
& h^{*}=\left(\frac{s_{k}^{\alpha} s_{h}^{1-\alpha}}{n+g+\delta}\right)^{\frac{1}{1-\alpha-\beta}}
\end{aligned}
$$

The relations (11) and (12) reveal the steady state of the economy. 
While taking into account the relation (5), we will have:

$$
\left(\frac{Y}{A L}\right)^{*}=\left(k^{*}\right)^{\alpha}\left(h^{*}\right)^{\beta}
$$

It means that:

$$
\left(\frac{Y}{L}\right)^{*}=(y)^{*}=A^{*}\left(k^{*}\right)^{\alpha}\left(h^{*}\right)^{\beta}
$$

The relation (13) represents the output by worker to the equilibrium.

At the equilibrium, the technological progress is represented by:

$$
A^{*}=A_{0} e^{\rho \theta}
$$

Where, $\rho$ represents the variables that correspond to the factors that can influence the technological progress. In our study, $\rho$ regroups the variables reflecting the global competitiveness.

The substitution of (11), (12) and (14) in (13), produces:

$$
(y)^{*}=A_{0} e^{\rho^{*} \theta}\left(\frac{s_{k}^{1-\beta} s_{h}^{\beta}}{n+g+\delta}\right)^{\frac{\alpha}{1-\alpha-\beta}}\left(\frac{s_{k}^{\alpha} s_{h}^{1-\alpha}}{n+g+\delta}\right)^{\frac{\beta}{1-\alpha-\beta}}
$$

To have a linear relation, we apply the logarithm:

$$
\operatorname{Ln}(y)^{*}=\operatorname{Ln}\left[A_{0} e^{\rho^{*} \theta}\left(\frac{s_{k}^{1-\beta} s_{h}^{\beta}}{n+g+\delta}\right)^{\frac{\alpha}{1-\alpha-\beta}}\left(\frac{s_{k}^{\alpha} s_{h}^{1-\alpha}}{n+g+\delta}\right)^{\frac{\beta}{1-\alpha-\beta}}\right]
$$

If we add the subscript of the time and the individual, we can write the following relation:

$$
\operatorname{Ln}\left(y_{i t}\right)^{*}=\operatorname{Ln}\left(A_{0 i}\right)+\theta_{i} \rho_{i t}+\frac{\alpha}{1-\alpha-\beta} \operatorname{Ln}\left(s_{k_{i t}}\right)+\frac{\beta}{1-\alpha-\beta} \operatorname{Ln}\left(s_{h_{i t}}\right)-\frac{\alpha+\beta}{1-\alpha-\beta} \operatorname{Ln}\left(n_{i t}+g+\delta\right)
$$

where, $\mathrm{g}$ and $\delta$ are supposed constant for all the countries and in the time and their sum is equal to 0.05 (Mankiw and al., 1992). The variable $\operatorname{Ln}\left(A_{0 i}\right)$ involves the structural factors and the factors of the economic environment possessing an influence on the economic growth. In our case, we took into consideration the factors of economic policies, to know the level of inflation and government expenditures.

Therefore, our regression is based on the following relation:

$$
L G D P_{i t}=\alpha+\beta \mathrm{GCI}_{i t}+\gamma L I N V E S T_{i t}+\lambda L E D U_{i t}+\tau L G_{i t}+\mu L I N F_{i t}+\varepsilon_{i t}
$$

where, "i" indicates the countries $(\mathrm{i}=1,2, \ldots, \mathrm{N})$ and " $\mathrm{t}$ " represents the time $(\mathrm{t}=1, \ldots, \mathrm{T}), L G D P$ : the logarithm of the GDP per capita calculated in constant dollars of 2000; GCI: the Global Competitiveness Index; LINVEST: the logarithm of the average yearly ratio of the investment in relation to the GDP; LEDU: the logarithm of the secondary schooling rate; $L G$ : the logarithm of the ratio of the public expenditures in relation to the GDP, $L I N F$, : the logarithm of the inflation ratio $(+1)$ calculated according to the consumer prices index and $\varepsilon_{\mathrm{it}}$ : is the error term.

All these variables are extracted from the yearly data of the World Bank data base (WDI), except for the data concerning the Global Competitiveness index which are extracted from "the Global Competitiveness Report", published by the World Economic Forum.

We estimated econometrically the last equation with the method of panel data for a sample of 23 African countries (Note 14) during the period 2004-2009.

The econometric analysis in panel data renders an account, both individual and temporal dimensions of the observations. A high number of observations permit us to take account of the individual differences of performances that is due to the influence of other factors that are considered in the regression.

The wealth of information in the estimation by panel data models lead to the following consequence: an important observed number of individuals allow great precision of the estimates.

While we estimate a sample with panel data, the first thing that it suitable to verify, is the homogeneous or heterogeneous specification of the generating process of the data. After that, we apply the individual-specific test to determine if we can suppose that the studied model is perfectly identical for all countries or each country have some specificities.

The presence of individual-specific effect makes the estimators of the Ordinary Least Square (OLS) not efficient. In these conditions, we must assess the estimation by the "within" method if these effects are fixed or by the Generalized Least Squares (GLS) method if these effects are random. 
The application of the individual specification test rejects the homogeneity hypothesis of the variables.

When the heterogeneity of the variables is detected, we must choose between either regression by "within" method or by the (GLS) method. To substitute between these two methods, we apply the Hausman (1978) specification test. Referring to the statistic of this test, we must use the "within" method to estimate the model with fixed effects which is convergent and efficient.

The principal results of the GDP per capita regression according to its determinants are recapitulated in table 2 .

Table 2. The results of the econometric regression (referring to the equation 18)

Endogenous variable is LGDP

\begin{tabular}{ccccccccc}
\hline GCI & LINVEST & LEDU & LPUBE & LINF & $\mathrm{C}$ & $\mathrm{N}$ & $\mathrm{R}^{2}$ & Hausman \\
\hline $0.107^{*}$ & $0.074^{* *}$ & $0.172^{*}$ & $-0.082^{*}$ & $-0.035^{*}$ & $5.511^{*}$ & 133 & 0.997 & $50.251^{*}$ \\
\hline
\end{tabular}

* Significant at $1 \% ; * * \quad$ Significant at $5 \% ; * * *$ Significant at $10 \%$.

The results of our estimation confirm that the level of global competitiveness, measured by the Global Competitiveness index (GCI) exercises a positive and statistically significant effect on the level of the GDP per capita in our sample constituted by a whole raft of African countries. The result can explain and justify the contribution of the evolution of global competitiveness level of the African countries during the last years of their economic growth. An evolution that is due to a number of economic reforms (Note 15) and to the political stability that characterized these countries. Thus, the fruits of these reforms are justified by the positive effect of the physical capital and human capital accumulation on economic growth.

The effect exercised by the global competitiveness of the economies, confirmed by our econometric regression, can also contribute to the potential transformation of the continent in concrete results in the next years. The African countries achieved great performances regarding economic growth, but the most important issue is on the one hand the achievement of continuity, and on the other hand, the development of the endogenous factors of wealth creation. These factors can operate on the competitiveness of their economies.

\section{Conclusion}

In this work we have tried to study the question of the economic growth in a sample of African countries and we came to a number of results. First, we showed how, in its evaluation of the global competitiveness of the different economies, the World Economic Forum take inspiration from the modern theories of economic growth (endogenous growth). Secondly, we presented the achievements during the last decade and the existing potential of the African continent concerning economic growth. Finally, by the means of panel data estimates for a sample of African countries during the period (2004-2009), we attempted to verify the contribution of the improvement of global competitiveness of these economies in their realization of increased economic growth.

\section{References}

Aghion, P., \& Howitt, P. (1992). A model of growth through creative destruction. Econometrica, 2, 323-351. http://dx.doi.org/10.2307/2951599

Barro, R. J. (1990). Government spending in a simple model of endogenous growth. Journal of Political Economy, 5 , 103-125. http://dx.doi.org/10.1086/261726

Gelb, A., Ramachandram, V., \& Turner, G. (2007). Stimulating growth and investment in Africa: From macro to micro reforms. African Development Review, 1, 25-56.

Grossman, G. M., \& Helpman, E. (1991). Innovation and growth in the global economy. Cambridge, Massachusetts, MIT Press.

Lucas, R. E. (1988). On the mechanisms of economic development. Journal of Monetary Economics, 1, 3-42. http://dx.doi.org/10.1016/0304-3932(88)90168-7

McKinsey, \& Company. (2010). Lions on the move: the progress and potential of Africa economies. McKinsey Global Institute.

O'Neill, J., \& Stupnytska, A. (2010). How Exciting is Africa's Potential. Strategy Series from the Office of the Chairman, October, 14. 
Pagano, M. (1993). Financial Markets and Growth: an Overview. European Economic Review, 37, 613-622. http://dx.doi.org/10.1016/0014-2921(93)90051-B

Romer, P. M. (1986). Increasing returns and long-run growth. Journal of Political Economy, 5, 1002-1037. http://dx.doi.org/10.1086/261420

Romer, P. M. (1990). Endogenous technological change. Journal of Political Economy, 5, 71-102. http://dx.doi.org/10.1086/261725

Thorsten, B., Fuchs, M., \& Uy, M. (2009). Finance in Africa: achievements and challenges. World Bank Working Papers, No 5020, pp 39.

World Development Indicators. (2010). World Economic Forum. The Global Competitiveness Report, different numbers, World Bank.

\section{Notes}

Note 1. Brazil, Russia, India and China

Note 2. O'Neill and Stupnytska (2010).

Note 3. The government can encourage the accumulation of this factor by decreasing its utilization cost, by the means of the subsidy instruments.

Note 4. This consists in producing new capital goods from a number of ideas resulting from the Searches \& Development activity.

Note 5. Private labor and physical capital.

Note 6. It is an institute of research of the McKinsey group that represents one of the principal international groups of economic and financial consultation.

Note 7. McKinsey \& Company (2010).

Note 8 . Either a fall of $64 \%$.

Note 9 . Either a decrease of $28 \%$.

Note 10. Either an amelioration of $60 \%$.

Note 11. McKinsey \& Company (2010).

Note 12. The use of (2009) like a year of our longitudinal estimates refers to the ending year in our empirical study, in the next paragraph.

Note 13. The choice of the countries of our sample is fixed by the availability of the data.

Note 14. Our sample is composed by these countries: South Africa, Botswana, Mauritius, Namibia, Gambia, Kenya Nigeria, Tanzania, Benin, Uganda, Cameroon, Zambia, Ethiopia, Malawi, Madagascar, Mozambique, Mali, Chad, Tunisia, Egypt., Morocco, Algeria and Zimbabwe.

Note 15. Privatization of the public companies, reduction of trade barrier, tax relief and consolidation of the legal systems. 